\title{
The Localization of Pharmaceutical Clinical Research in Europe
}

\author{
Greta Falavigna $^{1^{*}}$, Roberto Ippoliti² \\ ${ }^{1}$ Research Institute on Sustainable Economic Growth, National Research Council of Italy, Moncalieri, Italy \\ ${ }^{2}$ Department of Management, University of Turin, Turin, Italy
}

*Corresponding Author: Greta Falavigna, Ph.D., Assistant Professor, Research Institute on Sustainable Economic Growth, National Research Council of Italy, Moncalieri, Italy. Tel: +390116824941, Email: greta.falavigna@ircres.cnr.it

Received February 8, 2017; Accepted February 22, 2017; Online Published May 31, 2017

\begin{abstract}
Background: Clinical research is a specific phase of the production process in the pharmaceutical industry in which companies test candidate drugs on patients in order to collect clinical evidence about safety and effectiveness.

Objective: This paper is an operational research which aimed to support the hypothesis that pharmaceutical clinical research is like any other production process which could be localized where the cost is most competitive. In other words, this work aimed to demonstrate that the localization process of this specific phase of the pharmaceutical industry's R\&D is based on the price of clinical evidence.

Methods: Considering Europe and taking panel data into account, an efficiency frontier through data envelopment analysis (DEA) was estimated. The efficiency of countries in maximizing the number of innovative medical treatments, given their available resources was estimated. Afterwards, focusing on European macro-regions, authors analyzed whether a significant concentration of clinical research exists.

Results: Results suggest that, taking the expected principal investigators' fee into account, Southeastern Europe and Central Eastern Europe are the most attractive macro-regions for the pharmaceutical industry's foreign direct investments in clinical research.

Conclusion: The results of the proposed operational research cannot reject the suggested evolution of the pharmaceutical industry's clinical research. In other words, results confirm the localization process of the testing phase in East Europe, where the expected principal investigators' fee is more competitive.

Keywords: Clinical research, Pharmaceutical industry, Medical institution
\end{abstract}

\section{Background}

Clinical research is a specific phase of the production process of the pharmaceutical industry in which companies test candidate drugs on patients in order to collect clinical evidence about safety and effectiveness. This phase is shaped around several clinical studies in which potential research subjects are gradually involved. ${ }^{1}$

Information is essential to obtaining manufacture authorization from the national drug agency and, in this way, to make profits on the market. However, this information has a price. Pharmaceutical companies have to involve physicians (i.e. medical researchers) in this experimental activity, and normally there is a fee (i.e. economic incentive). Moreover, considering the ex-ante authorization process performed by Institutional Review Boards (IRBs) and their requirements, there are several bureaucratic costs before starting the enrollment process as well as insurance costs to cover unexpected risks. ${ }^{2}$ The final price of information should incorporate all costs necessary to collecting clinical evidence on candidate drugs. ${ }^{3-5}$ Should the price of this clinical evidence be competitive? Is it possible to hypothesize that clinical research could be localized where the price of this information is lower? In terms of a globalized market, could this specific phase of the pharmaceutical production process be localized just like any other productive process?

The very nature of clinical research suggests the necessity of localizing the experimental treatment somewhere since a sample of potential research subjects is necessary. Current literature analyzes the process of outsourcing medical research, suggesting that multinational corporations have started the localization process of clinical studies abroad. ${ }^{6-8}$

Current literature also suggests the existence of a market of human experimentation. ${ }^{3}$ It is a specific sub-market in which innovation is exchanged for information, where the former is given by experimental medical treatments, whereas the latter is given by clinical evidence on those experimental treatments. Taking Europe into account, an

Copyright (C) 2017 The Hospital Practices and Research. This is an open-access article distributed under the terms of the Creative Commons Attribution License (http://creativecommons.org/licenses/by/4.0), which permits unrestricted use, distribution, and reproduction in any medium, provided the original work is properly cited. 
empirical study on an imperfect kind of market has been proposed, a market in which the price of clinical evidence is the fee paid by pharmaceutical companies to physicians instead of the innovation behind the experimental treatment. ${ }^{9}$ However, there are still several open issues as well as potential developments of that research path, such as the study of national competitiveness with a specific methodology: data envelopment analysis (DEA). Indeed, the DEA approach will provide the possibility of describing and analyzing the efficiency of different countries in the European market of human experimentation. Efficiency is thought to be a country's ability to attract investments in this specific phase of the pharmaceutical industry's production process.

\section{Objective}

Considering Europe and taking the proposed background into account, this work aimed to support the hypothesis that the localization process of pharmaceutical clinical research is affected by the fee paid by pharmaceutical companies to medical researchers. According to the proposed thesis, the testing phase is moving from Western Europe to Eastern Europe, where the cost of clinical evidence is lower.

\section{Methods}

The main methodology applied in this study was DEA, a non-parametric technique which allowed the measurement of the performance of a subject and the assigning to it of a score representing its performance efficiency. ${ }^{10-13}$ This technique has been applied in many contexts to study relevant problems in the field of Operational Research, e.g., bank and credit risk applications, ${ }^{14,15}$ container ports, ${ }^{16}$ in the insurance industry, ${ }^{17}$ and, obviously, in the field of medical care. ${ }^{18-24}$

The output-oriented model was used, applying variable returns to scale (VRS). ${ }^{25-27}$ Moreover, a bootstrap procedure was applied to the DEA approach to correct score values and their confidence intervals, refined by the bias; the 2-stage approach was also used. ${ }^{28}$ In the first stage, the DEA output-oriented procedure with bootstrap was employed to estimate the efficiency of each European country. The output-oriented framework aimed at maximizing the output levels keeping the inputs constant. In other words, this work assumed that the inputs used cannot be easily changed, at least in the short term. In the second stage, the regression analysis aimed to show correlations between efficiency scores and a key explanatory variable.

The output of the model is represented by the number of medical facilities in which the experimental activities are performed. According to data availability, the input variables introduced in the DEA are all factors that might affect the national supply of clinical evidence: physicians and beds, as well as population. According to this approach, a country's efficiency can be imagined as its ability to maximize the number of proposed clinical trials for some given level of potential productivity factors.

Data about output considers exclusively the clinical trials of phases III, with pharmaceutical companies as sponsor. Studies of phases I, II, and IV are not considered, since the first involve healthy people, whereas the second and the third, regardless of the fact that they involve patients, are affected respectively by scientific and technological conditions and by marketing processes. Moreover, all types of studies have been included in the data-set (i.e. studies with pharmaceuticals, vaccines, devices, and procedures) as well as all medical facilities in which these activities are performed (i.e. both simple medical centers and highly specialized hospitals). Data was extracted from the online database of the U.S. National Institute of Health (https://clinicaltrials.gov, access: June 2011), and they refer to studies begun in Europe between 2000 and 2006. In this work Europe is considered as a group made up of 32 countries (Austria, Belgium, Bulgaria, Croatia, Czech Republic, Cyprus, Denmark, Estonia, Finland, France, Germany, Greece, Hungary, Ireland, Italy, Latvia, Lithuania, Luxemburg, Malta, the Former Yugoslav Republic of Macedonia, the Netherlands, Norway, Poland, Portugal, Romania, Slovakia, Slovenia, Spain, Sweden, Switzerland, Turkey, and the United Kingdom). The sample choice was affected by data availability and the necessity to respect the conditions of minimum technology, or the assumption that in each country of the considered sample all medical centers have those technologies necessary to implement a trial (e.g., medical laboratories). Data about inputs were extracted from the World Health Organization (WHO-European office) and the International Monetary Fund (IMF). The former database concerns the number of physicians working in health services (public and private) and the number of potential medical facilities (both variables are expressed per 100000 inhabitants), whereas the latter concerns the population of each European country. All inputs were normalized with a logarithmic transformation.

The number of physicians is essentially a measure of the potential number of medical researchers who could be involved in an experimental activity; the number of beds could be considered as a good proxy of the national health care system. Finally, in order to correctly balance the proposed output, the countries' populations were considered as input since they represent a dimensional variable of each observation within the European market. At the same time, this variable represents a proxy of the potential sample from which pharmaceutical companies can extract research subjects (i.e. enroll patients).

Taking the explanatory variable into account (i.e. the second stage), this paper attempts to explain national efficiency on the European market through macro-regions and economic growth. Taking political and cultural background into account, the European macro-regions considered by this work are the following:

- Northern Europe (Denmark, Finland, Norway, Sweden);

- Western Europe (Austria, Belgium, France, Germany, Ireland, Luxemburg, the Netherlands, Switzerland, the United Kingdom);

- Southern Europe (Cyprus, Greece, Italy, Malta, Portugal, Spain);

- Central Eastern Europe (Czech Republic, Hungary, 
Poland, Slovakia, Croatia, Slovenia);

- $\quad$ Southeastern Europe (Bulgaria, Romania, the Former Yugoslav Republic of Macedonia);

- Baltic Republics (Lithuania, Estonia, Latvia);

- Transcontinental (Turkey).

The countries' rates of income growth were considered as a proxy of national competitiveness (on the fee side) since it could be a consequence of localization of the production process (e.g., the manufacturing industry). ${ }^{9}$ Obviously, this work considered the European market as an open market in which pharmaceutical companies are free to localize their production process where they wish. In other words, companies are free to localize the testing phase anywhere throughout Europe, and, reasonably, they will consider information costs. This assumption is even more consistent if the human cost is considered as relevant within the testing phase of the pharmaceutical industry. According to this prospective, its localization should behave in the same way as other production processes, such as automobiles and clothing. ${ }^{29-31}$ In this work, the authors did not consider a specific component of the information cost, but of the whole cost (i.e. medical researchers' fee, bureaucratic costs, insurance, and so on), and for this reason, an aggregate index was proposed.

According to this approach, a specific index is proposed which is expressed in relation to the $n$ European countries average set to equal 100:

$W E A L H_{-} I N D E X_{i}^{t}=\left[\frac{W_{i}^{t}}{\sum_{i=1}^{n} W_{i}^{t} / n}\right]$

where $W$ is the gross domestic product (GDP) based on the purchasing-power-parity (PPP) per capita of the $i$-th country in the year $t$. This index can be a proxy able to measure how fast people's incomes increase in each country in comparison to the average of those countries. A positive correlation could either confirm or disprove a positive link between the localization of this specific phase of a pharmaceutical company's productive process and the competitiveness of this country on the European global market. The assumption is very clear: there is a positive index (i.e. the national income increases more than the average of the considered sample) if, and only if, the income is lower than the others (i.e. a higher competitiveness in the labor cost).

\section{Results}

Table 1 presents some descriptive statistics of inputs and outputs used in the DEA, while Table 2 shows the outcome of the first stage (i.e. efficiency scores) and the adopted explanatory variables (macro-regions and income index). Since data on the inputs was not available for all countries, there are only 194 observations instead of 224. Even though the sample is quite homogeneous, the standard deviation of outputs is high. Obviously, this result is ascribable to the degree of each observation (e.g., Malta vs. Germany).

One of the advantages of the DEA approach is the possibility of ranking observations based on their efficiency scores. Considering the efficiency scores, Figure 1 maps the European market of human experimentation in 2006.

This map suggests each country's position with respect to the European background, considering the number of medical facilities in which experimental activities are performed. Note that, according to the proposed methodology, a country is efficient if its score is equal to 1 ; moreover, since the bootstrap option has been applied, there are no countries with an absolute efficiency (i.e. a score equal to 1). For this reason, all observations have efficiency scores higher than 1 .

Table 3 suggests a descriptive statistic of the proposed

Table 1. Descriptive Statistics of Inputs, Output and the Outcome - Europe, 2000-2006

\begin{tabular}{llccccc}
\hline Type & Variable & Obs. & Mean & SD & Min. & Max. \\
\hline \multirow{3}{*}{ Inputs } & Population & 194 & 4.506 & 1.215 & 1.396 & 6.716 \\
& Physicians & 194 & 5.733 & 0.245 & 4.937 & 6.281 \\
& Beds & 194 & 6.327 & 0.338 & 5.375 & 6.816 \\
\hline Output & Medical centers & 194 & 201.304 & 332.633 & 1 & 2549 \\
\hline
\end{tabular}

Table 2. Descriptive Statistics of Dependent and Independent Variables - Europe, 2000-2006

\begin{tabular}{llllccc}
\hline Type & Variable & Obs. & Mean & SD & Min. & Max. \\
\hline Dependent Variable & Efficiency scores & 194 & 8.234 & 30.314 & 1.235 & 364.016 \\
\hline & Northern Europe & 194 & 0.144 & 0.352 & 0.000 & 1.000 \\
& Western Europe & 194 & 0.278 & 0.449 & 0.000 & 1.000 \\
& Southern Europe & 194 & 0.160 & 0.367 & 0.000 & 1.000 \\
& Central Eastern Europe & 194 & 0.180 & 0.386 & 0.000 & 1.000 \\
Explanatory variables & Southeastern Europe & 194 & 0.098 & 0.298 & 0.000 & 1.000 \\
& Transcontinental & 194 & 0.031 & 0.174 & 0.000 & 1.000 \\
& Baltic Republics & 194 & 0.108 & 0.311 & 0.000 & 1.000 \\
& Income Index & 194 & 4.447 & 0.529 & 3.327 & 5.611 \\
\hline
\end{tabular}




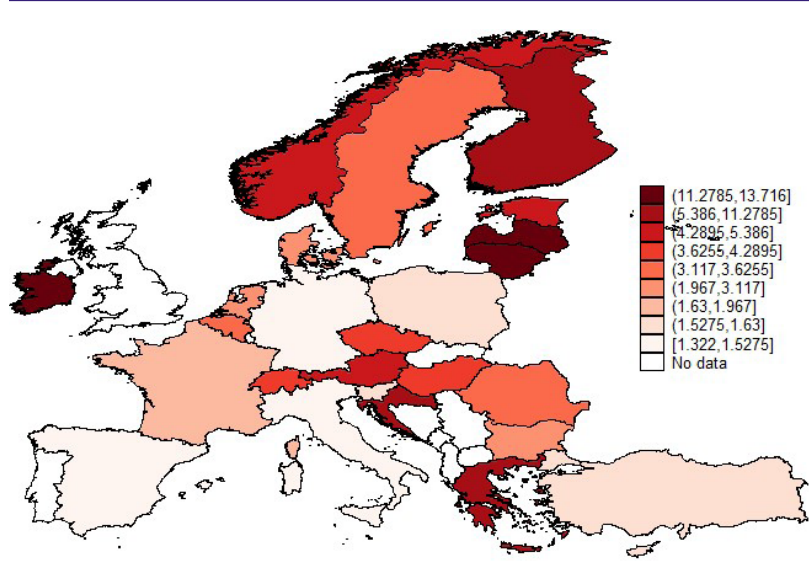

Figure 1. Mapping of Efficiency Scores - Europe, 2006.

income index and countries' trends between 2000 and 2006. In detail, this table suggests the average GDP on PPP of each country and, at the same time, its position with respect to the benchmark (sample mean). In other words, the proposed index denotes the gap (positive or negative) between the income of a country and the average of the considered sample of countries.
Table 4 shows the results of the second stage according to current literature. ${ }^{28}$ The results of two empirical analyses are shown: a truncated regression model (maximum likelihood methodology) and a multiple regression model (generalized least square methodology); in both cases, the bootstrap option was applied with 200 replications. Even if the literature suggests truncated regression as the most appropriate model, a multiple regression is also run in order to obtain more consistent results. ${ }^{28}$ Note that the panel data is not considered since the dataset is not balanced; therefore, a pooled sample is preferred. Moreover, to satisfy the normality assumption of variables, a logarithmic transformation was applied to the efficiency scores. Finally, note that the geographic area Transcontinental is the category against which the others were assessed. ${ }^{32}$

According to the Wald chi-squared test results, the hypothesis that all of the regression coefficients across both models are simultaneously equal to zero ( $P$ value equal to $.000)$ can be rejected. All variables have been plotted in order to justify the normality assumption with acceptable results along with the residuals of each analysis.

Table 3. Income Index and GDP on PPP - Europe, 2000-2006

\begin{tabular}{|c|c|c|c|c|}
\hline \multirow{2}{*}{ Country } & \multirow{2}{*}{$\begin{array}{c}\text { GDP on PPP } \\
\text { Mean }\end{array}$} & \multicolumn{3}{|c|}{ Income Index } \\
\hline & & Mean & SD & Variation \\
\hline Austria & 31633.738 & 134.87346 & 3.6057406 & $-7.45 \%$ \\
\hline Belgium & 29857.626 & 127.30126 & 3.3465746 & $-7.90 \%$ \\
\hline Bulgaria & 7981.783 & 33.70285 & 2.6829856 & $20.21 \%$ \\
\hline Croatia & 13380.930 & 56.72380 & 2.1939949 & $9.29 \%$ \\
\hline Cyprus & 25449.029 & 95.26115 & 1.2612819 & $-1.89 \%$ \\
\hline Czech Republic & 17985.618 & 76.25610 & 2.6013993 & $8.84 \%$ \\
\hline Denmark & 31207.102 & 133.04379 & 3.5889145 & $-7.36 \%$ \\
\hline Estonia & 13797.196 & 58.02047 & 7.1765051 & $29.28 \%$ \\
\hline Finland & 27982.958 & 119.06608 & 0.7052947 & $-0.94 \%$ \\
\hline France & 28606.981 & 122.04421 & 3.9964960 & $-9.33 \%$ \\
\hline Germany & 28789.229 & 122.84416 & 4.3916521 & $-9.35 \%$ \\
\hline Greece & 22666.160 & 96.20860 & 2.8306213 & $6.37 \%$ \\
\hline Hungary & 14843.963 & 62.87882 & 2.9478579 & $11.32 \%$ \\
\hline Ireland & 34588.577 & 146.96488 & 3.0259862 & $3.96 \%$ \\
\hline Italy & 26745.338 & 114.22083 & 5.0161251 & $-12.20 \%$ \\
\hline Latvia & 10835.480 & 45.49694 & 6.3241653 & $32.43 \%$ \\
\hline Lithuania & 11708.612 & 49.24019 & 6.0987289 & $28.51 \%$ \\
\hline Luxembourg & 68137.555 & 271.79465 & 2.2931338 & $1.19 \%$ \\
\hline Macedonia, Former Yugoslav Republic of & 6948.602 & 28.27603 & 0.3218756 & $2.55 \%$ \\
\hline Malta & 21203.533 & 79.35444 & 0.4341840 & $-0.78 \%$ \\
\hline Netherlands & 32676.579 & 139.33733 & 4.1434181 & $-7.49 \%$ \\
\hline Norway & 43781.848 & 186.56767 & 3.8294962 & $-6.06 \%$ \\
\hline Poland ${ }^{\Psi}$ & 13227.196 & 52.47744 & 1.1097370 & $4.98 \%$ \\
\hline Portugal & 18829.573 & 82.75966 & 3.6405067 & $-11.56 \%$ \\
\hline Romania & 8058.928 & 34.02339 & 2.7669527 & $20.15 \%$ \\
\hline Slovakia & 12796.609 & 57.46107 & 2.1642442 & $8.65 \%$ \\
\hline Slovenia & 22060.852 & 89.71704 & 1.7249174 & $4.81 \%$ \\
\hline Spain & 25432.221 & 108.33133 & 1.8821495 & $-3.79 \%$ \\
\hline Sweden & 29987.074 & 127.59933 & 0.7022088 & $-1.59 \%$ \\
\hline Switzerland & 34215.943 & 145.88535 & 4.0786662 & $-7.21 \%$ \\
\hline Turkey & 9605.676 & 39.74542 & 3.0482992 & $17.06 \%$ \\
\hline United Kingdom & 26789.971 & 125.80540 & 0.1501597 & $0.08 \%$ \\
\hline
\end{tabular}

Abbreviations: PPP, purchasing-power-parity; GDP, gross domestic product. 
Table 4. Truncated Regression Model $(\mathrm{A})^{\mathrm{a}}$ and Multiple Regression Model (B) - Europe, 2000-2006

\begin{tabular}{|c|c|c|c|}
\hline \multirow{2}{*}{ Variables } & \multicolumn{2}{|c|}{ A } & \multirow{2}{*}{$\begin{array}{c}\text { B } \\
\text { Efficiency Scores }\end{array}$} \\
\hline & eq1 & Sigma & \\
\hline \multirow[t]{2}{*}{ Northern Europe } & $7.299 * * *$ & & $7.297^{* * *}$ \\
\hline & $(1.933)$ & & $(1.922)$ \\
\hline \multirow[t]{2}{*}{ Western Europe } & $7.530^{* * *}$ & & $7.527^{* * *}$ \\
\hline & $(1.917)$ & & $(1.866)$ \\
\hline \multirow[t]{2}{*}{ Southern Europe } & $7.258^{* * *}$ & & $7.256^{* * *}$ \\
\hline & $(1.672)$ & & $(1.574)$ \\
\hline \multirow[t]{2}{*}{ Central Eastern Europe } & $5.825^{* * *}$ & & $5.823^{* * *}$ \\
\hline & $(1.251)$ & & $(1.172)$ \\
\hline \multirow[t]{2}{*}{ Southeastern Europe } & $5.341^{* * *}$ & & $5.336^{* * *}$ \\
\hline & $(1.353)$ & & $(1.172)$ \\
\hline \multirow[t]{2}{*}{ Baltic Republics } & $6.429 * * *$ & & $6.426^{* * *}$ \\
\hline & $(1.232)$ & & $(1.204)$ \\
\hline \multirow[t]{2}{*}{ Income Index } & $-4.738^{* * *}$ & & $-4.735^{* * *}$ \\
\hline & $(1.483)$ & & $(1.530)$ \\
\hline \multirow[t]{2}{*}{ Constant } & $19.066^{* * *}$ & $3.514^{* * *}$ & $19.057^{* * *}$ \\
\hline & $(5.544)$ & $(0.278)$ & $(5.820)$ \\
\hline Wald chi2(7) & \multicolumn{2}{|c|}{59.42} & 72.65 \\
\hline Prob > chi2 & \multicolumn{2}{|c|}{0.0000} & 0.0000 \\
\hline Year FE & \multicolumn{2}{|c|}{ Yes } & Yes \\
\hline Observations & 187 & 187 & 187 \\
\hline R-squared & & & 0.221 \\
\hline
\end{tabular}

Standard errors in parentheses.

*** $P<0.01$, ** $P<0.05$, * $P<0.1$.

a Upper level equal to 20.

\section{Discussion}

This work aimed to establish a correlation between the localization of a specific productive process in Europe, taking countries' competitiveness on the cost of clinical evidence into account. On one hand, the authors estimated efficiency scores, and on the other, they used these scores as dependent variables in regression models, adopting geographic areas and countries' rates of income growth as independent ones. According to the proposed hypothesis, the testing phase is a productive process with proper workers (i.e. physicians) and specific raw materials (i.e. patients) like any other production. Results cannot reject this positive correlation. In other words, this work supports the hypothesis that the pharmaceutical industry's investment is localized where the costs of clinical evidence are lower. Indeed, taking the Income Index into account, Southeastern Europe and Central Eastern Europe are the most efficient in attracting such foreign direct investments (i.e. the coefficients are significantly lower than in other areas). Focusing on the Income Index, results suggest that a positive trend (i.e. income growth) can raise national efficiency, and attract foreign direct investments by the pharmaceutical industry. Indeed, a negative coefficient means a positive impact on efficiency scores. Moreover, the results are robust since, even if the estimator model changes, the hypothesis is coherent in both models.

The next section proposes some final considerations considering the collected results.

\section{Conclusion}

According to the literature, participating in clinical trials would yield clear benefits for a society. Medical centers can contribute to the advancement of medical research and/ or ensure access to experimental treatments. ${ }^{33,34}$ Another key reason for participating in clinical trials is that they eliminate drug expenditure, which might have a significant economic impact on the whole healthcare system - its hospitals, pharmacies, and oncology units. ${ }^{35-38}$ Indeed, drugs might be supplied for free by the sponsor of a clinical trial, thus bringing about a substantial savings, which is even more significant considering the increasing price of chemotherapy. ${ }^{39}$ Therefore, considering the current age of austerity, there is a clear interest in raising national competitiveness on the market of human experimentation.

Innovatively, results support the hypothesis that pharmaceutical foreign direct investments in this specific phase are localized where the costs of clinical evidence are lower. The localization process of pharmaceutical clinical research is clearly affected by countries' competitiveness in fees. According to the proposed explanation, the testing phase is no different from other production processes characterized by labor intensive levels (e.g., the manufacturing industry) and, considering the labor costs, the emerging economies of Eastern Europe are more competitive. Which might be the best opportunity to raise competitiveness in the Western countries?

Considering Western Europe, in order to raise national competitiveness on the European market of human experimentation, the policy maker should work on several sides. One could be the system of incentives behind a physician's choice to be involved in the research activity, while another could be the regulation process (i.e. IRBs' authorization process). Several strategies could be used with the same target, i.e. trying to facilitate the exchange of clinical information for innovation between patients and pharmaceutical companies. Indeed, the current literature suggests that countries might increase (or decrease) their regulations, imposing more stringent (or more relaxed) safety and compensation requirements and, obviously, the natural consequence of this approach could be the localization of this process where the expected cost is lower. ${ }^{6,40}$ Is this risk acceptable? Can more relaxed regulation to raise national competitiveness be accepted?

Countries have to raise the efficiency of the regulation system with a reduction in the time necessary to collect clinical evidence instead of a reduction in patient safety. The necessity to work faster than others in the regulation process, forgetting the real target of a protection system, might induce IRBs and/or medical researchers to adopt wrong choices. Indeed, competition might hit the target but miss the point. Obviously, the policy maker should consider the consequences of these opportunities before the implementation of new regulations. Health policy should be shaped considering the opportunity to minimize the required time to review a trial while simultaneously preventing potential collusion among the main actors (i.e. IRBs, the pharmaceutical industry, and medical researchers) versus the weakest one (i.e. patients). 


\section{Research Highlights}

\section{What Is Already Known?}

The current literature has analyzed the process of outsourcing medical research, suggesting that multinational corporations like Pfizer, Eli Lily, GlaxoSmithKline, Sanofi Aventis, and Roche have started the localization process of clinical studies abroad, with India, Indonesia, Thailand, Mexico, Brazil, South Africa, and China as their preferred destinations.

\section{What This Study Adds?}

Considering the European market of human experimentation, this work supports the hypothesis that Southeastern Europe and Central Eastern Europe are the most attractive macro-regions for the pharmaceutical industry's foreign direct investments in clinical research.

This work makes contributions to raising the current scientific knowledge on the pharmaceutical industry's foreign direct investments, but there are also weaknesses. The greatest weakness of this work deals with the composition of the cost of clinical evidence (bureaucratic cost, physicians' fee, etc.). Indeed, there is no available micro-data about its composition. An analysis of the cost composition could be an opportunity to improve this work and raise the current knowledge, if such data becomes available.

\section{Authors' Contributions}

RI and GF contributed equally to this manuscript.

\section{Conflict of Interest Disclosures}

No conflicts of interest.

\section{Ethical Approval}

According to current regulation, ethical authorization was not necessary for this study.

\section{References}

1. Ippoliti R. Human experimentation. In: Encyclopedia of Law and Economics. New York: Springer; 2016:1-3. doi:10.1007/978-14614-7883-6_237-1.

2. Ippoliti R. Institutional Review Board. In: Encyclopedia of Law and Economics. New York: Springer; 2015:1-4. doi:10.1007/978-1-4614-7883-6_197-1.

3. Ippoliti R. The market of human experimentation. European Journal of Law and Economics. 2010;35(1):61-85.

4. Ippoliti R. Economic efficiency of countries' clinical review processes and competitiveness on the market of human experimentation. Value Health. 2013;16(1):148-154. doi:10.1016/j.jval.2012.09.010.

5. Ippoliti R, Falavigna G. Public health institutions, clinical research and protection system of patients' rights: an impact evaluation of public policy. Public Organ Rev. 2012;14(2):109125. doi:10.1007/s11115-012-0208-5.

6. Adobor $\mathrm{H}$. Ethical issues in outsourcing: the case of contract medical research and the global pharmaceutical industry. J Bus Ethics. 2011;105(2):239-255.

7. Santiago-Rodriguez F. Facing the trial of internationalizing clinical trials to developing counties: with some evidence from Mexico. Working Paper Series. United Nations University, Maastricht, The Netherlands; 2008:1-26.

8. Jia $\mathrm{H}$. Chinese manufacturers vie for piece of outsourcing pie. Nat Biotechnol. 2007;25(12):1337-1338. doi:10.1038/ nbt1207-1337.

9. Ippoliti R. Clinical research, an empirical work on the European market of human experimentation. J Public Health. 2011;20(4):461-475. doi:10.1007/s10389-011-0472-9.

10. Cook W, Seiford L. Data envelopment analysis (DEA) - Thirty years on. Eur J Oper Res. 2009;192(1):1-17.

11. Charnes A, Cooper W, Rhodes E. Measuring the efficiency of decision making units. Eur J Oper Res. 1978;2(6):429-444.

12. Fare R. Intertemporal Production Frontiers. 1st ed. Boston: Springer; 2012.

13. Coelli TJ, O’Donnell CJ, Rao DSP. An Introduction to Efficicency and Productivity Analysis. 1st ed. Springer; 2005.

14. Fethi M, Pasiouras F. Assessing bank efficiency and performance with operational research and artificial intelligence techniques: A survey. Eur J Oper Res. 2010;204(2):189-198. doi:10.1016/j. ejor.2009.08.003

15. Ray S, Das A. Distribution of cost and profit efficiency: evidence from Indian banking. Eur J Oper Res. 2010;201(1):297-307.

16. Hung S, Lu W, Wang T. Benchmarking the operating efficiency of Asia container ports. Eur J Oper Res. 2010;203(3):706-713. doi:10.1016/j.ejor.2009.09.005

17. Barros C, Nektarios M, Assaf A. Efficiency in the Greek insurance industry. Eur J Oper Res. 2010;205(2):431-436. doi:10.1016/j.ejor.2010.01.011

18. Chen A, Hwang Y, Shao B. Measurement and sources of overal and input inefficiencies: evidences and implications in hospital services. Eur J Oper Res. 2005;161(2):447-468. doi:10.1016/j. ejor.2003.09.017

19. Dlouhy M, Jablonsky J, Novosadova I. Use of data envelopment analysis for efficiency evaluation of Czech hospitals. Politicka Ekonomie. 2007:55:60-71.

20. Pulina $M$, Detotto $C$, Paba $A$. An investigation into the relationship between size and efficiency of the Italian hospitality sector: a window DEA approach. Eur J Oper Res. 2010;204:613-620. doi:10.1016/j.ejor.2009.11.006.

21. Piacenza M, Turati G, Vannoni D. Restructuring hospital industry to control public health care expenditure: the role of input substitutability. Econ Model. 2010;27(4):881-890. doi:10.1016/j.econmod.2009.10.006.

22. Garavaglia G, Lettieri E, Agasisti T, Lopez S. Efficiency and quality of care in nursing homes: an Italian case study. Health Care Manag Sci. 2011;14(1):22-35. doi:10.1007/s10729-0109139-2.

23. Ippoliti R, Falavigna G. Efficiency of medical care industry: evidence from the Italian regional system. Eur J Oper Res. 2012;217:643-652. doi:10.1016/j.ejor.2011.10.010.

24. Rezaei S, Dopeykar N, Barouni M, Jafari M, Gharibi F. Do hospitals affiliated with the kurdistan university of medical sciences perform efficiently? Non-parametric data envelopment analysis. Hospital Practices and Research. 2016;1(4):135-140.

25. Farrell MJ. The measurement of productive efficiency. J R Stat Soc Series A. 1957;120(3):253-290.

26. Banker RD, Charnes A, Cooper WW. Some models for estimating technical and scale inefficiencies in data envelopment analysis. Manage Sci. 1984;30(9):1078-1092.

27. Cooper WW, Seidorf LM, Tone K. Data Envelopment Analysis. A Comprehensive Text With Models, Application References and DEA-Solver Software. 2nd ed. Berlin: Springer; 2007

28. Simar L, Wilson PW. Estimation and inference in two-stage, semi-parametric models of production processes. J Econom. 2007;136:31-64. doi:10.1016/j.jeconom.2005.07.009.

29. Hudson R. Changing industrial production systems and regional development in the new Europe. Trans Inst Br Geogr. $2002 ; 27(3): 262-281$

30. Carstensen K, Toubal F. Foreign direct investment in Central and Eastern European countries: a dynamic panel analysis. Comp Econ. 2004;32:3-22. 
31. Bevan A, Estrin S. The determinants of foreign direct investment into European transition economies. J Comp Econ. 2004;32:775-787.

32. Suits DB. Use of dummy variables in regression equations. J Am Stat Assoc. 1957;52(280):548-551.

33. Gelber RD, Goldhirsch A. Can a clinical trial be the treatment of choice for patients with cancer? J Natl Cancer Inst. 1988;80:886-887.

34. Peppercorn J, Weeks JC, Cook EF, Joffe S. Comparison of outcomes in cancer patients treated within and outside clinical trials: conceptual framework and structured review. Lancet. 2004;363:263-270. doi:10.1016/S0140-6736(03)15383-4.

35. Bredin C, Eliasziw M, Syme R. Drug cost avoidance resulting from cancer clinical trials. Contemp Clin Trials. 2010;31(6):524529. doi:10.1016/j.cct.2010.09.004.

36. Shen LJ, Chou H, Huang CF, Chou GM, Chan WK, Wu FL.
Economic benefits of sponsored clinical trials on pharmaceutical expenditures at a medical center in Taiwan. Contemp Clin Trials. 2011;2(4):485-491. doi:10.1016/j.cct.2011.04.003.

37. Rogers S.D., Lampasona V., Buchanan E.C The financial impact of investigational drug services. Top Hosp Pharm Manage. 1994;14(1):60-6.

38. McDonagh MS, Miller SA, Naden E. Costs and savings of investigational drug services. Am J Health Syst Pharm. 2000;57:40-43.

39. Jönsson B, Wilking N. The burden and cost of cancer. Ann Oncol. 2007;18(3):iii9-22.

40. Koenig P, MacGarvie M. Regulatory policy and the location of bio-pharmaceutical foreign direct investment in Europe. J Health Econ. 2011;30(5):950-965. doi:10.1016/j. jhealeco.2011.07.005. 